\title{
REVIEW
}

\section{The management of work-related asthma guidelines: a broader perspective}

\author{
Xaver Baur*, Tor Brøvig Aasen\#, P. Sherwood Burgeø, Dick Heederik', \\ Paul K. Henneberger ${ }^{\S}$, Piero Maestrelli ${ }^{f}$, Vivi Schlünssen**, \\ Olivier Vandenplas ${ }^{\# \#}$ and Dennis Wilken* on behalf of the ERS Task Force on the \\ Management of Work-related Asthma"
}

ABSTRACT: The aim of the European Respiratory Society work-related asthma guidelines is to present the management and prevention options of work-related asthma and their effectiveness.

Work-related asthma accounts for $\mathbf{5 - 2 5 \%}$ of all adult asthma cases and is responsible for a significant socioeconomic burden. Several hundred occupational agents, mainly allergens but also irritants and substances with unknown pathological mechanisms, have been identified as causing work-related asthma.

The essential message of these guidelines is that the management of work-related asthma can be considerably optimised based on the present knowledge of causes, risk factors, pathomechanisms, and realistic and effective interventions. To reach this goal we urgently require greatly intensified primary preventive measures and improved case management. There is now a substantial body of evidence supporting the implementation of comprehensive medical surveillance programmes for workers at risk. Those workers who fail surveillance programmes need to be referred to a clinician who can confirm or exclude an occupational cause. Once work-related asthma is confirmed, a revised risk assessment in the workplace is needed to prevent further cases. These new guidelines confirm and extend already existing statements and recommendations.

We hope that these guidelines will initiate the much-needed research that is required to fill the gaps in our knowledge and to initiate substantial improvements in preventative measures.

KEYWORDS: Agents, compensation, legal adjudication, occupational asthma, socioeconomic impact

W ork-related asthma has become one of the most common occupational diseases. Its annual incidence is in the range of 50 to 140 cases per million workers and can even reach 1,300 cases per million in certain workplaces [1]. Some $5-25 \%$ of new cases of adult asthma can be directly attributed to work-related exposure [2-6]. This will be discussed further in the "Socioeconomic impact" section. Frequently, sensitisation and newonset occupational asthma occur in the early period of exposure to high molecular weight (HMW) agents. However, workers continue to develop new sensitisations and upper, as well as lower, airway diseases can arise at a later date [7]. The ongoing risk was especially evident in the longer follow-up studies of ELLIOTT et al. [8] and KRUIZE et al. [9]. Similar relationships exist for occupational chronic obstructive pulmonary disease (COPD), which typically occurs after long-term exposure and shows some overlap with work-related asthma $[10,11]$. Thus, physicians continue to be confronted with a consistently high number of patients with work-related obstructive airway diseases. This was reiterated recently by the American Thoracic Society (ATS) who declared that "the clinician must be aware of the potential occupational etiologies for obstructive airway disease and consider them in every patient with asthma or COPD" [4]. These disorders result in a huge socioeconomic burden on individual affected workers and on society. These disorders are preventable and their incidence can be reduced substantially by appropriate primary prevention. Furthermore, the prognoses and financial burden can be improved within a framework of
AFFILIATIONS

*Institute for Occupational and Maritime Medicine, University Medical Center Hamburg-Eppendorf Hamburg, Germany.

\#Dept of Occupational Asthma, Haukeland University Hospital, Bergen, Norway.

'Dept of Respiratory Medicine, Heart of England NHS Foundation Trust, Birmingham, UK

+Environmental Epidemiology Division, Institute for Risk Assessment Sciences (IRAS), University of Utrecht, Utrecht, The Netherlands.

${ }^{\S}$ National Institute for Occupational Safety and Health, Centers for Disease Control and Prevention, Morgantown, WV, USA.

${ }^{f}$ Dept of Environmental Medicine and Public Health, University of Padova, Padua, Italy.

**Dept of Environmental and Occupational Medicine, School of Public Health, Arhus University, Århus, Denmark.

\#\# Dept of Chest Medicine, MontGodinne Hospital, Université Catholique de Louvain, Yvoir, Belgium.

"For a full list of the members

of the Task Force, see the

Acknowledgements.

\section{CORRESPONDENCE}

$X$. Baur

Institute for Occupational and Maritime Medicine, University Medical Center

Hamburg-Eppendorf, Seewartenstrasse 10, 20459 Hamburg, Germany

E-mail: baur@uke.de

Received:

June 072011

Accepted after revision:

July 212011

\section{PROVENANCE}

Submitted article, peer reviewed. European Respiratory Review Print ISSN 0905-9180 Online ISSN 1600-0617 
secondary prevention, i.e. by early diagnosis within the window of opportunity of a few months after the onset of symptoms [12]. In addition, a reliable diagnosis in an index case (a sentinel event) may reveal risks for other similarly exposed workers, leading to a revised risk assessment that should reduce the risk for other exposed workers. Adequately optimised secondary and tertiary preventive interventions may enable affected workers to continue working productively, benefitting all concerned.

The motivation for the Task Force was therefore to produce guidelines to facilitate early diagnosis, enabling a swift response to prevent new causes of work-related asthma occurring in the future and to make improvements in the management, preventative measures, regulations and compensation. These guidelines are mainly directed towards new onset asthma induced by workplace allergens, agents with unknown pathomechanisms and irritants. However, aggravation of pre-existing asthma by workplace exposure and occupational COPD are also briefly addressed and some consideration is given to other work-related airway disorders (such as asthma-like symptoms and occupational rhinitis).

\section{CAUSAL AGENTS}

Several hundred agents in the workplace have been reported to cause allergic asthma, asthma of unknown pathomechanisms or irritant-induced asthma [13-15], with new causes being described regularly in the medical literature (data not shown). Systematic reviews of analytical studies [16] demonstrate that the most frequently reported agents include isocyanates, flour and grain dust, colophony, soldering fluxes, latex, animals, aldehydes and wood dust [17-27]. The predominant agents and jobs commonly reported in surveillance schemes of occupational asthma in different countries were recently summarised [1, 28, 29]. An analysis of a case series from the US SENSOR surveillance programme for occupational diseases revealed similar adverse consequences for both work-related asthma and work-aggravated asthma, but differences in the most common exposure agents (diisocyanates versus mineral and organic dust) [30]. The occupations most commonly reported to surveillance schemes for occupational asthma are paint sprayers, bakers and pastry makers, nurses, chemical workers, animal handlers, welders, food processing workers, hairdressers and timber workers $[17,18,21-26,31,32]$. Registries generally record one to 20 cases per 100,000 [28]. The most informative study is the one by HENNEBERGER et al. [33] because of its capture-recapture strategy. Additionally, there is moderate evidence from well-conducted population-based analytical studies that workers in certain occupations are at an increased risk of developing asthma [16]. These incorporate the same range of occupations or industries and include bakers, food processors, and forestry, chemical, plastic, rubber, metal, textile, storage, farm, electrical and electronic production workers, as well as welders, waiters, cleaners, painters, plastic workers, dental workers and laboratory technicians [34-37].

There is strong evidence from high-quality systematic reviews of analytical studies that the risk of sensitisation and occupational asthma is increased by many workplaces [9, 16, 38-61]. CHANG-YeUnG and MALO [62] summarised the results from cross-sectional studies on work-related asthma in different workplaces with prevalence of $1 \%$ and $>50 \%$ among the exposed workers. The prevalence of work-related asthma was related to the causative agent and exposure level, but was over- or underestimated depending on the disease definition (by questionnaire, immunological assessment, lung function testing and from specific or nonspecific challenge) and selection effects. Prevalence was especially high for some HMW agents (such as flour proteins and enzymes) and a few low molecular weight (LMW) agents (such as platinum salts).

\section{SOCIOECONOMIC IMPACT The burden of work-related asthma}

Asthma currently is one of the most common chronic diseases in the world [63]. Moreover, the proportion of work-related asthma in the population is high, as indicated by both population-based epidemiological surveys [34, 36, 37, 64] and workforce-based studies [21, 26, 27, 34, 36, 37, 64-66].

The proportion of asthma due to occupational exposure in population-based studies is between $5 \%$ and $25 \%$ in the European Community Respiratory Health Survey (ECRHS) [6, 37], but $17 \%$ in females and $29 \%$ in males in a Finnish study [64]. The British Occupational Health Research Foundation (BOHRF) [16] reported strong evidence from high-quality systematic reviews of analytical studies that the annual population incidence of occupationally related asthma has a range of 12 to 170 cases and an estimated mean of 47 cases per million workers [5, 17, 22, 32], which is higher than that reported from registries. Occupational factors were estimated to account for $9-15 \%$ of cases in adults of working age, including both new onset or recurring disease $[4,5]$. In a systematic analysis from 19 countries, initiation in the workplace was suspected in $10 \%$ of all cases of adult-onset asthma [5]. In a recent systematic analysis, TOREN and BLANC [2] estimated that the population-attributable fraction was now as high as $17.6 \%$. Another review of 21 studies demonstrated an attributable risk of $15 \%$ [4]. KARJALAINEN et al. [32] reported the highest figure from compulsory reporting to state authorities of suspected work-related asthma cases in Finland for the period 1989-1995. However, there is evidence that the real incidence of work-related asthma in Finland is even higher. One crosssectional study found some evidence that the population incidence of occupational asthma may be underestimated by as much as 50\% [67]. NEWMAN TAYLOR et al. [16] found limited evidence from non-analytical studies that the incidence of occupational asthma has not decreased in recent years [19, 31, 68]. One study indicated that the growth of childhood-onset asthma is followed by a corresponding increase in pre-existing asthma in the workforce when these asthmatic cohorts enter their working lives [69]. The incidence of work-related sensitisation per person-yr varied in a prospective study among apprentices in occupations with a high risk of developing work-related asthma from $2.5 \%$ for pastry making to $8.9 \%$ for exposure to laboratory animals [70]. In addition, physician-diagnosed data [66] and registry studies [21] are in line with these findings, although generally show lower figures. The latter may be due to national, institutional and insurance regulations and restrictions, as well as the heterogenicity and quality differences in diagnostics and medical expert opinions.

Based on the literature, several recommendations from early diagnosis of work-related asthma must be taken into consideration from these findings. 1) Employers, health and safety personnel and health practitioners should be aware that at least one in 10 cases of new or recurrent asthma in adult life is 
attributable to the occupation of the sufferer (BOHRF; Royal College of General Practitioners (RCGP) three-star system; Scottish Intercollegiate Guidelines network (SIGN), level A) [71]. 2) Work-related asthma should be suspected in all adult-onset asthmatics whose asthma began while at work (Canadian guideline: level 2A) [72]. 3) An occupational role (cause or aggravation) should be considered in all working asthmatics (Canadian guideline: level 2A) [72].

\section{Economic aspects}

The costs can be divided into direct and indirect costs. The direct costs (i.e. medications, physician consultations, emergency room visits and hospitalisations) are similar on average for occupational and non-occupational asthma of similar severity $[73,74]$. Indirect costs affect the worker, the employer and the state. The worker suffers lost income. For the employer the costs include lost productivity from sickness absence and labour turnover, and compensation and insurance costs. The costs for the state include compensation, unemployment support and loss of tax revenues.

Studies from different countries are difficult to compare because of differences in approach and cost allocation structures between different insurance and healthcare systems. These differences include the definition of cost components, the variable provision of medical services by the state and private sector, and whether the study considered all affected people or only adults of working age. Mindful of these difficulties, the results of the studies suggest an annual total cost ranging from approximately $€ 4,600$ to $€ 9,670$ per "average" afflicted person (at 2004 prices) [74, 75]. The costs of occupational asthma were shown to vary substantially depending on the severity of the disease, with a minority of individuals with severe asthma accounting for a disproportionately large share of the total costs. The studies also showed that workers with occupational asthma suffer adverse employment and financial consequences. In general, the financial consequences were consistently more pronounced in workers who avoided further exposure to the substance that caused occupational asthma. A considerable proportion of workers with occupational asthma continue to suffer from exposure to the causative substance in order to avoid or minimise the loss of income resulting from unemployment. The total (lifetime) costs include the costs of those diagnosed in a particular year together with continuing costs of those diagnosed in previous years who may remain unemployed, on reduced income or in receipt of benefits, and whose asthma usually continues.

A study in the UK considered occupational asthma diagnosed in 2003 and neglected work-aggravated asthma and occupational COPD [76]. It showed the following key results. 1) The 'average' worker suffering from occupational asthma lost 3.5 to 4.5 working days per year. A worker with milder or more severe occupational asthma was estimated to lose approximately two or 10 working days per year, respectively. 2) The total number of newly reported cases of occupational asthma in the UK in 2003 was 631 (442 males and 189 females). 3) The estimated total lifetime costs to society of these new cases of occupational asthma ranged from $€ 85.02$ million to $€ 118.6$ million; or approximately $€ 4.3$ million to $€ 5.69$ million per year over the lifetime of the disease. 4) For male workers, the estimated total lifetime costs to society range from $€ 63.54$ million to $€ 92.47$ million, which equates to approximately $€ 143,453$ to $€ 208,713$ per worker. 5) Allowing for the fact that the number of new cases of occupational asthma diagnosed in 2003 is under reported by up to one-third, the total lifetime cost to society could be as high as $€ 113.92$ million to $€ 159.12$ million. 6) The estimated total lifetime costs to society are made up of costs incurred by the individual, employers and the state (taxpayers). The largest cost burden falls on the individual worker (who incurs $\sim 49 \%$ of total costs), followed very closely by taxpayers (incurring $\sim 47 \%$ of total costs). In contrast, the employers of workers diagnosed with occupational asthma in 2003 only incurred $\sim 4 \%$ of the total costs. 7 ) There appears to be little incentive for employers to reduce the incidence of new cases of occupational asthma in the UK, despite the fact that significant benefits would accrue for the rest of society; benefits to the state and employees could be as high as $€ 83.09$ million and $€ 114.76$ million, respectively, over the lifetime of those workers diagnosed with the disease in 2003. 8) This pattern of cost burden suggests that employers are imposing a significant 'external' cost onto the rest of society.

The costs of occupational asthma have also been estimated in the USA. Assuming that $15 \%$ of adult asthma is attributable to workplace exposure [5], LEIGH et al. [77] estimated the total cost of work-related asthma to be $\$ 1.6$ billion in 1996, which included $\$ 1.17$ billion $(76 \%)$ in direct costs. Based upon this estimate, work-related asthma accounted for $0.13 \%$ of the total US healthcare expenditure. Similar (or more) costs must also be incurred from work-related COPD, for which no published data is available.

\section{Adverse consequences for the affected workers}

Follow-up studies of workers with occupational asthma have consistently documented that the condition is associated with a high rate of prolonged work disruption or even permanent unemployment (14-69\%) and loss of income (44-74\%) [75, 78, 79]. The financial consequences of occupational asthma are more pronounced in workers who avoid further exposure to the causal agent. Notably, the lowest rates of unemployment (14$25 \%$ ) have been reported in countries (i.e. Finland and Canada) where a high proportion of workers with occupational asthma actually do benefit from effective job retraining programmes. A lower level of education and being older are also associated with a worse socioeconomic outcome. Retraining possibilities for a new occupation are often ineffectual, especially in older workers [78, 79]. The severity of asthma does not appear to be an important determinant for the socioeconomic outcome in subjects with occupational asthma, with the exception of one cohort of Finnish workers with isocyanate-induced occupational asthma [80]. The disease-related loss of income is only offset by the financial compensation awarded in a minority of affected workers. Recent data indicate that subjects with workrelated asthma show higher healthcare resource utilisation than asthmatic subjects without work-related symptoms [81]. There is evidence that occupational asthma is associated with an adverse impact on healthcare resource utilisation [81], quality of life $[80,82,83]$ and mental well-being $[83,84]$.

There are only scarce data available for workers suffering from work-aggravated asthma [85] and none for those suffering from occupational COPD. It can be assumed that their outcome 
does not differ substantially from that already described for the occupational asthma sufferers.

\section{PREDICTION MODELS, PREVENTION AND INTERVENTION}

The diagnosis of work-related asthma usually follows a work-up by a physician after patient referral. The worker usually seeks medical help actively. This differs from health surveillance programmes in which the worker is passive and invited by health professionals within a framework of secondary prevention. The final diagnosis rarely arises from the result of one test. It is the result of individual medical professionals interpreting consecutive test results and estimating the probability of the presence of a disease or other outcome of interest. However, many test results generate more or less identical information. It is important, therefore, to evaluate the independent and additionally predictive value of a test given the presence or absence of earlier information.

Prediction research offers a solution by using a multivariate approach in design and analysis that accounts for mutual dependencies between different test results. The information content of every item can then be translated into a predicted probability of the chosen outcome. This technique allows weights to be given to each independent predictor in the probability equation, and provides estimates of the probability of an outcome currently (diagnosis) or in the future (prognosis).

Prediction models applied in occupational health practice may enable occupational physicians to deal with uncertainties when considering workers at risk for occupational disease. The main goal is to optimise risk estimation at low cost and, where possible, to determine the first step in the clinical evaluation and management of work-related asthma [86-90]. The models may initiate counselling and intervention, as well as being useful for identification of specific groups at risk. In the article by WILKEN et al. [91] in the current issue of the European Respiratory Review, the use of a questionnaire-derived screening tool in a medical surveillance programme for work-related asthma in HMW allergen-exposed and irritant-exposed workers is demonstrated. This relatively new and transparent approach to medical surveillance is medical triage based on a diagnostic model developed to predict the probability of developing work-related asthma.

\section{Primary and secondary prevention}

Epidemiological data indicate that the level of exposure to sensitising agents is the most important determinant of immunoglobulin (Ig)E-mediated sensitisation and occupational asthma, which implies that reducing or eliminating the respective workplace exposure should be the most effective approach for minimising the incidence of the disease [92]. The same is true for airway irritants whose adverse effects are typically concentration dependent.

The most important measure of secondary prevention in affected workers is the avoidance of causative exposure. If this is not possible, there should be significant reduction of exposure and the responsible use of appropriate personal protection devices, especially respirators, as a last resort [93]. There is also a role for better education of trainees about the risks of sensitisation (fig. 1) [94].

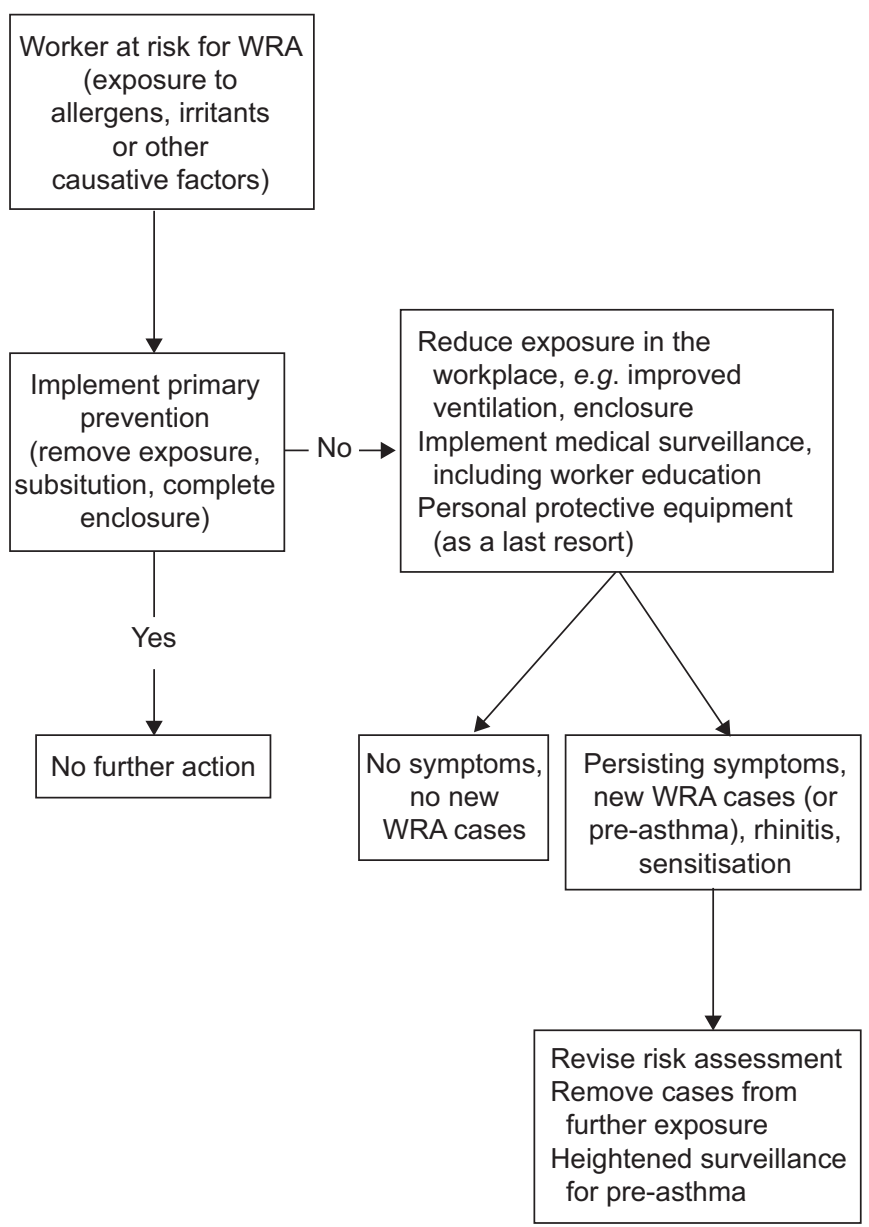

FIGURE 1. Primary and secondary prevention in case of increased risk of work-related asthma (WRA). For further information refer to the Management of Work-related Asthma guidelines [12] and the study by WILKEN et al. [91].

Therefore, management and treatment strategies should focus on avoidance of exposure to the agent causing allergic or irritant airway disorders. Exposure can usually be avoided by relocating the worker to unexposed areas or to duties within the same company after appropriate retraining, or rigorous technical changes to the production process. However, complete avoidance of exposure often implies considerable changes in profession for the affected workers and a substantial socioeconomic disadvantage [95-97]. Therefore, reduction of exposure may be considered a reasonable alternative for workers with mild irritant asthma, providing the worker undergoes regular medical surveillance.

Examples of effective prevention resulting from elimination or reduction of exposure by technical means have been documented in enzyme detergent production [98], platinum-refining workers [99], laboratory workers [100] and healthcare workers using latex gloves [101]. The strongest evidence on the effectiveness of exposure reduction comes from replacement of powdered latex gloves by non-powdered latex or non-latex gloves. There is some doubt about the effectiveness of exposure reduction strategies in other situations, because exposure reduction has often been accompanied by a reduction in exposed workers by mechanisation or automation, reducing the number 
of occupational asthma cases by reducing the population at risk. Whether the risk for an individual worker was actually reduced because of exposure reduction could not always be ascertained. However, reducing exposure to safe levels remains extremely difficult in practice, because the threshold level (or dose) of an agent that can elicit sensitisation and respiratory reactions is largely uncertain due to inadequacies in study design [102]. In addition, exposure reduction often requires a combination of technological and organisational efforts. Few interventions are as simple as changing to a different glove type as was the case for latex exposure in healthcare.

Medical surveillance must also consider individual risk factors [103], such as sensitisation to relevant occupational allergens [91] and differences in individual susceptibility. Furthermore, since workers demonstrating nonspecific bronchial hyperresponsiveness (NSBHR) and allergic rhinitis have a higher risk of developing asthma [104-108], it might be reasonable to counsel such workers to completely avoid exposure. However, the positive predictive values of available susceptibility markers are too low for screening out potentially susceptible individuals $[71,94]$. This is particularly true in the case of atopy and smoking, which are highly prevalent in the general population. Excluding atopic individuals from jobs entailing exposure to HMW allergens would dramatically reduce the number of potential new employees and would be unduly discriminatory [92]. Medical surveillance aims to identify susceptible workers. As outlined by HEEDERIK et al. [92], comprehensive medicalsurveillance programmes should be performed, especially in high-risk groups such as subjects with rhinitis, NSBHR or sensitisation, or those exposed to HMW allergens or high concentrations of irritant chemicals. It may include pre-placement and periodic administration of a questionnaire, skin-prick tests or measurement of specific serum $\operatorname{IgE}$ antibodies when there is exposure to a respiratory allergen, and early referral of symptomatic and/or sensitised workers for specialised medical assessment. These worker-related investigations necessitate accompanying exposure assessment in the workplace and appropriate interventions targeted at the workers as well as in the workplace [91]. The frequent short latency period for the development of occupational asthma $[7,45,106,109]$ means that surveillance programmes for individuals at risk need to begin during vocational training.

\section{General aspects of intervention}

Decision making, such as in the implementation of an intervention strategy, is a core component of medical practice where the focus is utilitarian rather than scientific goals [110]. Prevention has its own ethical, anthropological and economical dilemmas, which necessitate a clear distinction between assessment of scientific evidence and decision making for intervention. Even if a diagnostic method has proven efficacy, the effectiveness in clinical practice might be substantially less. The use of scarce health resources also has to be evaluated along existing guidelines [111, 112].

\section{Who will decide?}

In clinical practice, most decisions are made within the framework of the patient-doctor relationship. In prevention, however, the medical practitioner will often have the authority to guide and advise on decisions about secondary effects and prevention in individuals. But executive authority regarding making necessary changes to reduce or eliminate the relevant exposure is usually the responsibility of the employer and relevant professionals, including safety engineers and occupational hygienists. Public authorities might have the right to enforce regulations, which can also be revised after a new hazard has been identified. The role of the physician will often be as an advisor, together with other technical and environmental or hygiene specialists. The quality of the evidence will often determine which decisions are made. Prevention of a new hazard might commit employers to making large investments over extended periods of time.

Describing the consequences of alternative decisions is a crucial element of decision making [110, 113]. The different diagnostic possibilities have to be enumerated and the probability of alternative events described. Most importantly, the utility of different outcomes must be evaluated. These may be in health-related units (e.g. mortality, morbidity or quality of life) or in financial terms. The consequences for the various protagonists must be known, for exposed workers, employers or for society in general. In a decision model, the accuracy of a diagnostic test may be incorporated in order to evaluate the consequences of either a false positive or false negative diagnosis. This may better define the required level of accuracy of diagnoses for optimising the use of diagnostic resources.

With regard to risk analysis, identification of cases, hence diagnosis, is essential to perform a correct risk assessment [114]. A framework for risk assessment for allergens resulting in exposure standards has been proposed recently [102]. Since heavy burdens of irritants and allergens, as well as the presence of occupational rhinitis and NSBHR, are acknowledged risk factors for development of work-related asthma, they all have to be taken into consideration when targeting intervention strategies. The physician will play an important role in prevention by describing the hazards and assessing the risk, which is an obvious prerequisite for effective reduction or elimination of a hazard.

\section{MEDICO-LEGAL AND SOCIOECONOMIC ASPECTS OF WORK-RELATED ASTHMA}

Within the framework of the patient-doctor relationship, the prevention of work-related asthma and occupational COPD can only be achieved to a limited extent. Of greater immediacy are the medico-legal and socio-political conditions, including worker legal and economic rights, ethical codes, the economic strength of the industries, as well as decisions made by regulatory bodies and employers that may involve substantial investment to reduce disease risk and morbidity from asthma. These factors, which vary considerably between countries and over time, have an impact on the prevention, management and compensation of occupational diseases.

Essential tasks for the specialist in occupational pulmonary diseases are the provision of research- and evidence-based risk estimates, proposals for risk management and advice to policy makers.

\section{Heterogeneity of legal adjudication in different countries}

In Europe, insurance for occupationally related diseases is organised by either private or public insurance companies, the 
state, or is not distinguished from other health insurance systems (e.g. in the Netherlands). Most medically confirmed cases of work-related asthma are neither acknowledged nor compensated as occupational diseases, generally because of the legal status in a particular country.

The European list of occupational diseases [115, 116], which is not legally binding, currently includes: allergic rhinitis caused by the inhalation of substances consistently recognised as causing allergies and inherent to the type of work (code 304.07); allergic asthmas caused by the inhalation of substances consistently recognised as causing allergies and inherent to the type of work (code 304.06); lung diseases caused by the inhalation of dust and fibres from cotton, flax, hemp, jute, sisal and bagasse (code 304.02); respiratory ailments caused by the inhalation of dust from cobalt, tin, barium and graphite (code 304.04); chronic obstructive bronchitis or emphysema in miners working in underground coalmines (code 307); and bronchopulmonary ailments caused by dusts or fumes from aluminium or compounds thereof (code 309) or caused by dust from basic slags (code 310) [115]. Irritant-induced asthma and occupational COPD are not included.

Although most European countries have specific lists for the presumptive agents of occupational asthma, insurance and compensation systems are rather heterogenous [117] with statutory employer insurance requirements in some countries such as Austria, Finland, Germany and Switzerland. In most European countries, work-aggravated asthma is not acknowledged as an occupational disease or it is not differentiated from new-onset asthma and occupational COPD (such as in Germany) (table 1).

In countries following a predefined implementation schedule for occupational disease, a claimant who develops a listed disease has a strong likelihood of receiving a compensation award. However, claims for a disease not on restricted lists are more likely to be unsuccessful, which usually encourages the worker to seek other sources of social assistance. In the UK, Germany and France, an implementation schedule is used, which can be broadened in its application. In Germany this is possible if new scientific evidence identifies a novel occupational cause in a well-defined occupational exposure context.

Lists of compensable occupational diseases in most European countries differ greatly from worker compensation systems in the USA, where the systems vary from state to state [117, 121]. Disputes in occupational asthma are formidable, with diagnosis, causality and disability usually decided by litigation in an adversarial proceeding [122]. Evidence from lay persons and expert witnesses is presented to adjudicators appointed by the compensation board. Because asthma may often be caused by non-workplace conditions, the vast majority of these claims often go to litigation without success. Experience of the diagnosing physician with the rules of the compensation system may be important for the success of the claim [121].

After acknowledgement of occupational asthma, relevant medical expenses are paid by the self-insured employer or the state compensation fund [123]. Compensation wages usually equal about two-thirds of the predictable income, but only up to a maximum. Compensation is only granted if objective disability is shown but not if only impairment exists.

\section{Pre-product screening}

Attempts to identify the likelihood of an agent acting as a respiratory allergen (sensitiser), prior to widespread use by humans, have been mainly performed using animal models [124]. For example, using a mouse intranasal test, the potencies of several protease and nonprotease enzymes causing specific IgG1 production varied 60-fold [125]. More broadly, the hazard evaluation of LMW agents always includes an assessment of their dermal sensitisation potential. In most cases, this is now performed using an animal-based local lymph node assay, which tests the ability of topically applied chemical agents to induce proliferative lymphocyte responses in draining nodes [126]. Cytokine fingerprinting may offer a more specific index of respiratory sensitising potential [127-129]. Arguably, chemicals that are positive in a test involving dermal application should be considered as sensitisers regardless of their mode of contact with the body, including through inhalation [130]. However, it has not yet been assessed whether chemicals that are negative in skin sensitisation tests are thereby unlikely to cause respiratory sensitisation.

A different approach involves structure activity analysis for LMW agents $(<1,000 \mathrm{Da})$ [131, 132]. Nitrogen- or oxygencontaining functional groups, such as isocyanate, amine, acid anhydride and carbonyl, were associated with an occupational asthma hazard, particularly when the functional group was present twice or more in the same molecule. A logistic regression model using only statistically significant independent variables for occupational asthma hazard correctly assigned $90 \%$ of the model development set. The external validation showed a sensitivity of $86 \%$ and specificity of $99 \%$. Whether such an approach is generally applicable requires further investigation.

A key objective of the new European Union legislation REACH (Registration, Evaluation, Authorization, and Restriction of Chemicals) is to promote sustainable industrial development and reduce health risks associated with use of chemicals [133]. $\mathrm{REACH}$ is designed to encourage substitution of those chemicals and processes with a negative impact on health and the environment. Although REACH is not directly aimed at the working environment, and more focused on the consumer, it will have an impact because it prescribes under which circumstances workers may handle chemicals. The exposure scenarios for different processes have to be established and the health risks for exposed workers remain to be evaluated as well. However, several large groups of sensitising agents are partially or totally exempt from the REACH process. Enzymes used for technical applications (e.g. detergents and textiles) have required a preregistration since 2008 and full registration from 2010 onward, depending on the tonnage involved. In contrast, enzymes used in food and animal feed are exempt from REACH registration because they are seen as agents required for the process but not present in the end product. Many natural substances and bulk products, like latex and wheat flour, are excluded from REACH as well. REACH also does not cover agents which have "no owner (producer)" that can be attributed, such as allergens from animals or combustion products like diesel or exposure to microorganisms. This means that REACH does not cover several important allergens and irritants with an undisputed public health impact, and that it is crucial to set exposure standards under existing policies. However, standard setting for asthmainducing agents does have major limitations in applicability to 


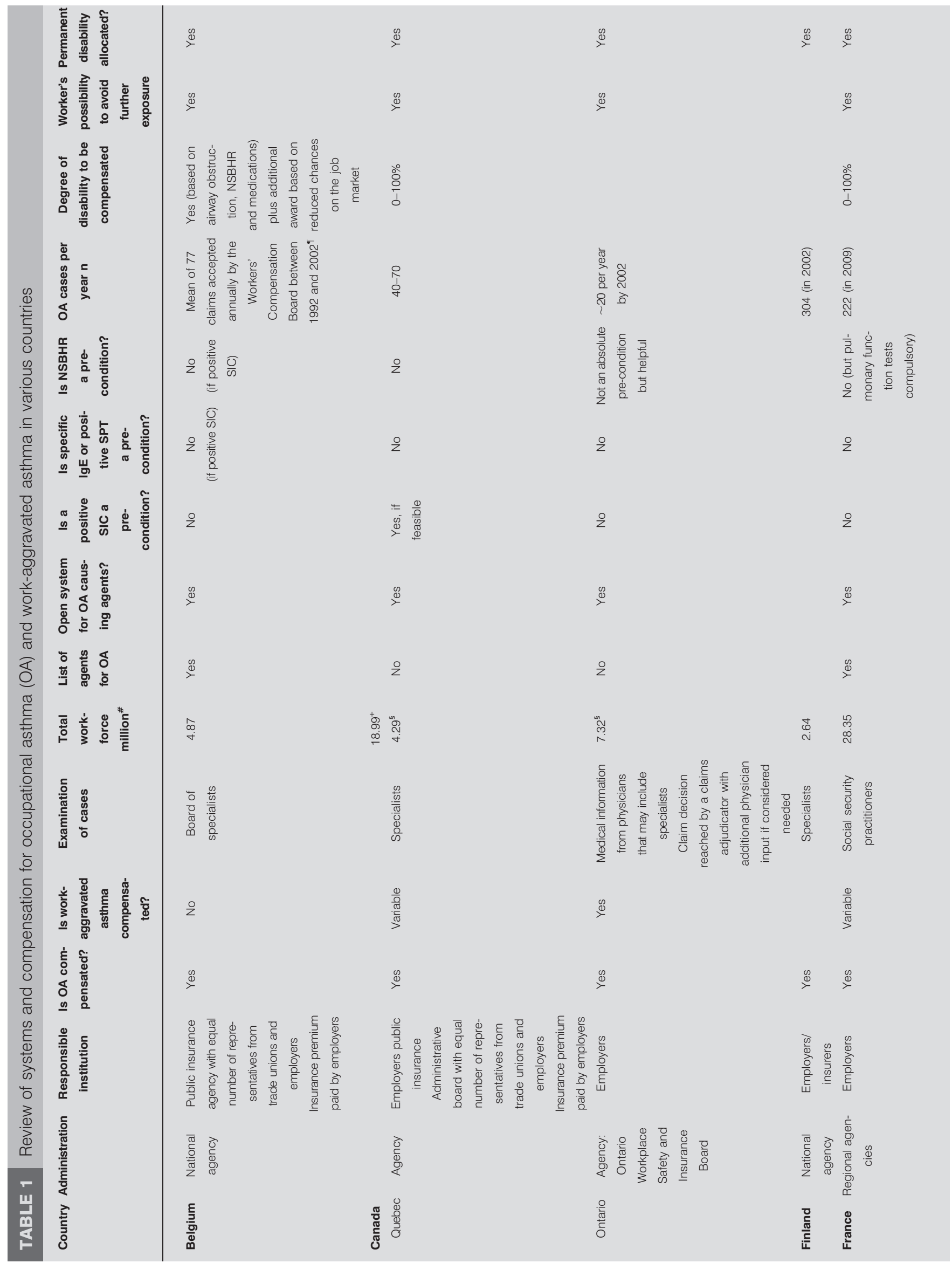




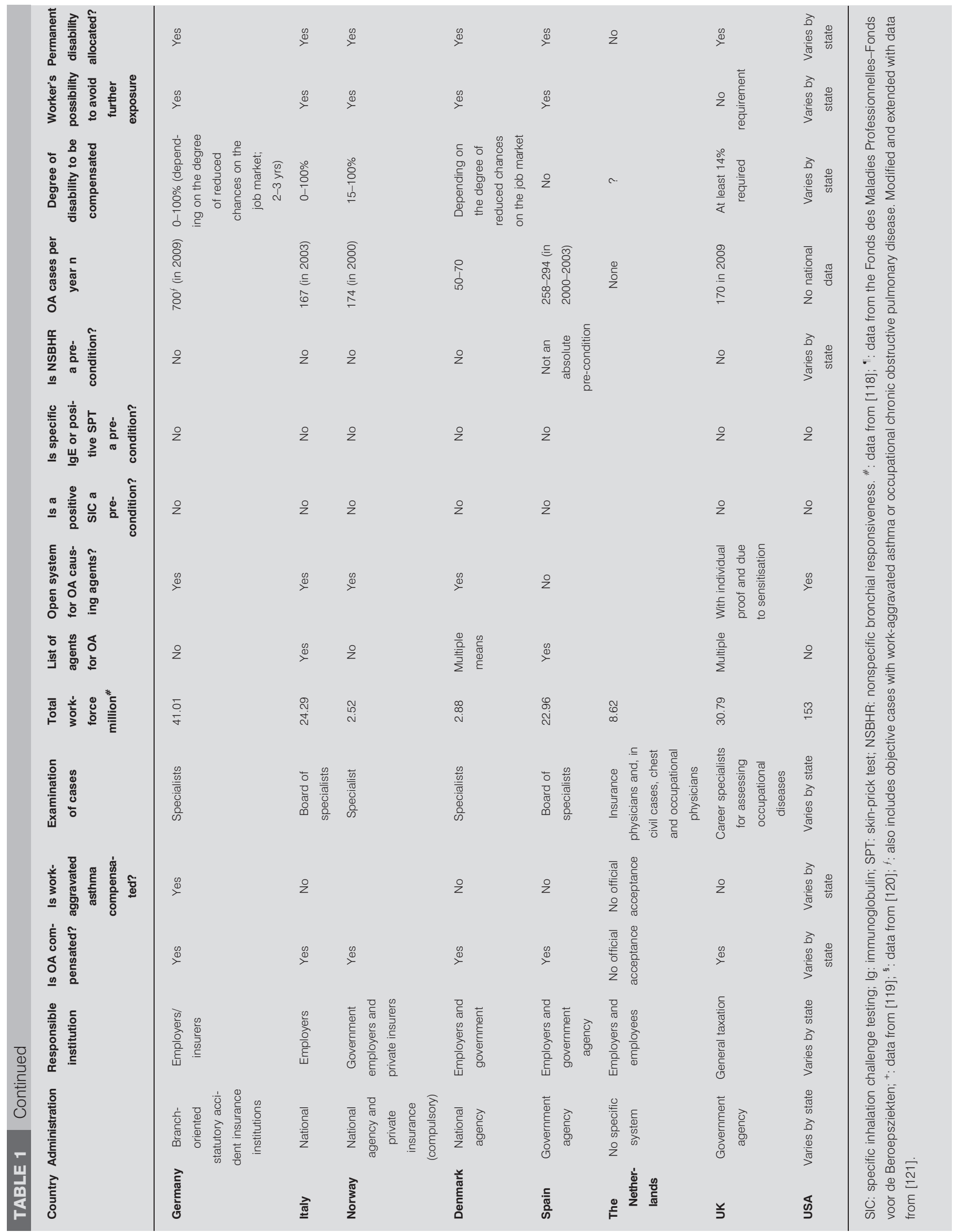


workers and exposure, although a recent study identified that scientifically based exposure standards may be derived for respiratory sensitisers [102].

\section{Compensation issues}

Since persistence of exposure to an agent causing work-related asthma leads to a worsening of the disease, prevalent patients should be considered disabled on a permanent basis for the job that caused the condition, as well as for jobs with a similar risk of exposure. The severity of these disorders should be assessed according to acknowledged grading schemes [10, 134-140].

The policies governing compensation of respiratory disorders vary widely from one country to another (table 1). These differences are caused by a number of factors, including administrative regulations and different criteria for definitions, determination of causality and evaluation of disability level. The criteria used for determining eligibility for compensation are not uniform and, depending on regulations of a particular country, may cover different aspects of physiological impairment, work disability, loss of income, healthcare costs and professional retraining. The available data for occupational asthma, however, indicates that financial compensation does not adequately offset the socioeconomic consequences of the disease [97, 141] and there is strong evidence that the same applies to work-aggravated asthma and occupational COPD. A growing consensus considers that compensation systems should be directed at accommodating workers in non-endangering (unexposed) jobs, if possible within the same company, and to offer structured rehabilitation programmes when required [71].

\section{PROBLEMS LIMITING THE SUCCESSFUL PREVENTION OF WORK-RELATED ASTHMA}

By identifying high-risk individuals and tailoring intervention programmes to them, it is possible to target preventative efforts successfully [142]. NICHOLSON and co-workers [71, 143], referring to the "Guidelines for the prevention, identification, and management of occupational asthma", mention that, to date, the principal recommendations of focusing on "regular health surveillance" are in accordance with this general opinion. In their concluding recommendations, the authors emphasise the importance of early identification of symptoms, including rhinitis, with additional functional tests and appropriate immunological tests. The effective management of workers suspected of having workrelated asthma or occupational COPD should focus on respiratory symptoms as soon as they occur, and should include spirometry also in the case of COPD. Unfortunately, other problems limit the success of preventive measures: the complexity of identification of early disease stages, the impact of different exposure characteristics on respiratory health and the limited knowledge of the associated health gain.

Most of the evidence mentioned in existing guidelines is derived from studies typically conducted in a clinical setting among workers known to have the disease and another group of unaffected individuals, rather than workers simply suspected of being afflicted. The cited studies generally follow a single-test or univariable approach, focusing on a particular test to measure its sensitivity, specificity or predictive value quantifying the test characteristic, rather than the contribution of the test in estimating the probability of the disease presence or absence.
The second reason that research results from tests have limited relevance is that the predictive value of a test (including personal history findings, which are diagnostic tests as well) vary not only across different populations but also within a particular study population and, therefore, may have different sensitivities and specificities. This is because all diagnostic information from questionnaires and additional tests is, to some extent, dependent on the underlying disorder and, thus, mutually influences the respective sensitivity, specificity and likelihood ratios. Thus, a single value for a particular test cannot exist, either of sensitivity, specificity, likelihood ratio or predictive value, which applies to all workers at risk of workrelated asthma or occupational COPD.

\section{LIMITATIONS OF THE CURRENT WORK}

There is a possibility of bias in publication selection in any review of the available literature. In addition, some studies may not have been found because of the MeSH terms used. A further limitation was that not all studies presented data in a form useful for evaluation and many studies included in the diagnoses and management sections displayed considerable heterogeneity. A major limitation of the available management literature is that the methodological quality was relatively weak and randomised controlled trials are not a relevant method of study design for most of the research issues in occupational diseases. They are generally not performed on ethical grounds. The majority of outcome assessments were not comparable and they tended to focus on physiological test results, with the interventions being generally heterogeneous and any allocation not being randomised.

The limits of "evidence-based medicine and alternative approaches" have often been enumerated [110, 113] and, similarly, the paradigm of "evidenced-based medicine" has been criticised by leading scientists [144-147]. Inevitably, selection and information bias may be a problem for generalisability of findings in single studies [148, 149]. It can also be questioned whether the hierarchy of evidence applied, e.g. by the BOHRF group [16, 150], is as appropriate for prevention as it is useful for evaluation of asthma treatment. There are few well-designed diagnostic studies that evaluate alternative strategies for evidence-based medicine, which makes the adoption of a better approach more difficult to achieve. YAMADA et al. [151] consider that physicians who properly practice evidence-based medicine use both individual clinical expertise and the best available external evidence, not one to the exclusion of the other. "Without clinical expertise, practice risks becoming tyrannized by evidence, for even excellent external evidence may be inapplicable to or inappropriate for an individual patient. Without current best evidence, practice risks becoming rapidly out of date, to the detriment of patients" [152].

Frequently, physicians misinterpret evidence-based medicine as an entity that is a direct application of the evidence, i.e. randomised controlled trials and other prospective studies, systematic reviews and meta-analyses. This is a common misunderstanding that overlooks the more thoughtful identification and compassionate use of individual patient predicaments, rights and preferences in making clinical decisions about their care [153]. Accordingly, in order to avoid such "cookbook medicine", practitioners using evidence-based 
medicine must integrate the evidence with clinical expertise and patient values to apply the results in clinical practice [154].

Neither evidence-based medicine, public health nor the process of applying evidence to decision making can be divorced from historically contingent programmes driven by instrumental rationality. An excessive focus on the instrumentally rational course makes us lose sight of the role of values to decide among courses of action. If not reconsidered, policy makers will utilise the mantle of evidence-based public health to justify decisions based on the instrumentally rational needs rather than on considerations such as social justice. Our moral sensibilities are shaped by knowledge of history, narratives, the arts and the realities of our lives and all are pertinent when setting public health policy.

\section{CURRENT GUIDELINES AND CONSENSUS STATEMENTS Canadian Thoracic Society}

The Canadian guidelines for occupational asthma were published in 1998 [72]. These national guidelines for the diagnosis and management of work-related asthma were the first evidencebased guidelines in this field. The definitions of the levels of evidence were taken from the 1996 report on the working groups for the Canadian Asthma Consensus Conference [155]. The methodology of the review is divided into consensus statements, followed by a review of the rationale for the statements. 15 recommendations and an indication of the rigor of the evidence follow the narrative text. The guidelines are mainly aimed at the family doctor, internal medicine physician, general practitioner/ pneumologist and occupational physician, who frequently encounter patients with work-related asthma.

\section{BOHRF}

The BOHRF guidelines were published in 2005 [71] and updated in 2010 [143]. The aim of the BOHRF guidelines was to improve the prevention, identification and management of occupational asthma in primary care and in occupational health settings, by providing evidence-based recommendations on which future practice and management could be based. The BOHRF guidelines consist of 53 evidence statements with ratings of the strength of that evidence, using both the SIGN system of 2000 [156] and the Royal College of General Practitioners (RCGP) three-star system of 1995 [157]. Furthermore, they provide 22 recommendations (in 2010, after restructuring, 11 key recommendations and five good practice points), graded using the revised SIGN system and the RCGP three-star system, and good practice points where evidence was lacking. The BOHRF guidelines are aimed at physicians and nurses working in general practice, occupational health and respiratory medicine, and at employers, safety representatives and workers who may be exposed to substances at work that can cause asthma. The BOHRF guidelines focus on interventions that are considered appropriate for implementation by health practitioners or employers and supplement other guidelines that are available for the clinical management of adult asthma.

\section{Agency for Healthcare Research and Quality}

In 2005, a systemic review by BEACH et al. [148] was published on the diagnosis and management of work-related asthma [28]. Different levels of evidence were compiled for the three types of work-related asthma: work-related asthma with latency of allergic or presumed immunological mechanism; work-related asthma without latency; and work-aggravated asthma. The key questions of the report were to ascertain the following: what is the best diagnostic approach for a patient with suspected workrelated asthma, what are the advantages of specific inhalation challenge (SIC) testing, and in what situations would SIC provide additional useful diagnostic information? Furthermore, the authors considered which measures/treatments were most effective for work-related asthma, e.g. removal from work versus reduced exposure with medical treatment (e.g. inhaled steroids) and whether patients with work-related asthma should be removed from the workplace environment to control symptoms and/or disease progression. Prevention of work-related asthma was not part of the scope of the report. In this evidence-based analysis, 124 cohort studies that met general inclusion criteria were reviewed in order to determine which methods were effective in diagnosing occupational asthma. A quantitative analysis was precluded by the heterogeneity of the many sources and the variations in sensitivity and specificity in respect of what constitutes a positive test result. The authors computed a set of pooled sensitivities and specificities of sensitiser-induced workrelated asthma using a random effects model, after performing a weighted pooling of means and standard deviations to combine results within studies. Six diagnostic methods were compared and evaluated for sensitivity and specificity, with SIC being the most commonly identified reference standard among the 124 studies. Among all chemical agents responsible for occupational asthma, diisocyanates and wood dust were the top two causes. SIC, as the reference test, was compared with other diagnostic tests. SIC showed a similar sensitivity among positive subjects as two or three comparison tests (especially NSBHR testing and specific skin-prick test (SPT)) for HMW agents, but it showed higher sensitivity than SPT among LMW agents when only SIC-positive subjects were included in the studies. The authors suggested a combination between NSBHR and specific SPT or IgE could enhance the specificity of diagnostic tests. However, sensitivity could not be increased by any combination of these tests. The authors also warned against over-interpretation of these results, because some issues make SIC problematic as a reference standard, such as the likelihood of a false negative test for some asthma-inducing agents or the heterogenous criteria used to signify a positive SIC test among the various studies. Without doubt, specificity of diagnosis can be increased by combining diagnostic tests, although which tests should be combined depends on the sensitivity and specificity of the tests themselves and their cost-effectiveness.

\section{American College of Chest Physicians consensus statement}

The American College of Chest Physicians (ACCP) update [142] of the previous 1995 consensus statement is concurrent with a 2008 British Thoracic Society document on the standard of care for occupational asthma [158]. The ACCP consensus document defined work-related asthma to include occupational asthma (i.e. asthma induced by exposure to a sensitiser or irritant at work) and work-exacerbated asthma (i.e. work-aggravated asthma), with pre-existing or concurrent asthma worsened by work factors. The distinguished expert panel conducted a systematic review and provided a set of graded recommendations for all aspects of occupational asthma, from diagnosis through treatment to prevention. This work also deals with the role of the 
physician in promoting safer employment options and access to workers compensation. The consensus document focused on the diagnosis and management of work-related asthma (including diagnostic tests, work and compensation issues), as well as preventive measures. It is stated that diagnostic tests such as serial peak flow recordings, methacholine challenge tests, immunological tests and SIC tests (if available), can increase diagnostic certainty. The major findings and recommendations made by the expert panel are as follows.

Work-related asthma is a major component of adult-onset asthma. It is recommended that the diagnosis must be considered in all who present with new-onset or worsening asthma, followed by appropriate investigations and intervention including consideration of other exposed workers.

In individuals with suspected sensitiser-induced occupational asthma, conducting an SIC (where available) is suggested when the diagnosis or causative agent remains equivocal; however, this testing should only be performed in specialised facilities, with medical supervision throughout the testing. The panel reviews and discusses the many limitations of immunological testing (skin-prick or serological) as an adjunct to diagnosis of work-related asthma for exposure to HMW substances; these tests are of little use with LMW agents and of no use in irritantinduced asthma. Diagnostic tests, such as serial peak flow recordings or methacholine challenge tests, can also increase diagnostic certainty. Since the prognosis is better with early diagnosis and appropriate intervention, effective preventative measures for other workers with exposure should be addressed.

\section{CONCLUSION}

The scope of these guidelines concerns management and prevention options for work-related asthma and their effectiveness, including diagnostic approaches, identification of risk factors, strategies for screening, surveillance, prevention and optimal treatment for affected individuals. We approached this topic by conducting systematic evaluations of the existing evidence from published literature and other sources. The guidelines are presented in the context of causes, the heterogenous legal adjudication in Europe, socioeconomic aspects, and other guidelines and consensus statements.

The prognosis of work-related asthma is frequently worse than with non-work-related asthma cases, but improves with early diagnosis and removal from exposure. Therefore, reliable and applicable diagnostics are required, followed by appropriate interventions that minimise exposures and other health risks to the affected worker and prevent further diseases in co-workers.

Within this framework, the role of the physician in the management of cases, the promotion of a safe work environment and the facilitation of access to adequate compensation cannot be overestimated. Other urgent requirements include international improvements in and standardisation of the relevant health regulations, and compensation which facilitates a return to useful employment in addition to compensating resulting disability.

The proposed guidelines confirm and extend already existing statements and recommendations from the Canadian Thoracic Society, BOHRF, the Agency for Healthcare Research and Quality and the ACCP.
Hopefully, the implementation of these guidelines will rapidly lead to changes in legislation and working practices which will significantly reduce the incidence and severity of occupational airways diseases. This will be of benefit to the employers, workers and society as a whole.

\section{SUPPORT STATEMENT}

The work of the Task Force on the Management of Work-related Asthma was funded by the European Respiratory Society.

\section{STATEMENT OF INTEREST}

P.S. Burge has developed the OASYS system for the analysis of serial measurements of peak expiratory flow in the diagnosis of occupational asthma. The system is freely available at www.occupationalasthma. com. He has never received any money related to this. He is an unpaid member of other groups creating related evidence-based guidelines (BOHRF for occupational asthma and SIGN/BTS for asthma). He is an expert witness in legal cases related to occupational asthma. $\mathrm{V}$. Schlünssen received a fee for speaking at a scientific meeting from GlaxoSmithKline Pharma A/S in 2011.

\section{ACKNOWLEDGEMENTS}

The members of the Task Force are as follows: X. Baur (Chair; Institute for Occupational and Maritime Medicine, University Medical Center Hamburg-Eppendorf, Hamburg, Germany), T. Sigsgaard (Co-Chair; Århus University, Dept of Environmental and Occupational Medicine, School of Public Health, Aarhus, Denmark), T.B. Aasen (Dept of Occupational Medicine, Haukeland University Hospital, Bergen, Norway), P.S. Burge (Dept of Respiratory Medicine, Heart of England NHS Foundation Trust, Birmingham, UK), H. Dressel (Städt. Klinikum München $\mathrm{GmbH}$, Klinikum Neuperlach Zentrum für Akutgeriatrie und Frührehabilitation, Munich, Germany), D. Heederik (Environmental Epidemiology Division, Institute for Risk Assessment Sciences (IRAS), University of Utrecht, Utrecht, the Netherlands), P.K. Henneberger (National Institute for Occupational Safety and Health, Centers for Disease Control and Prevention, Morgantown, WV, USA), P. Maestrelli (Dept of Environmental Medicine and Public Health, University of Padova, Padova, Italy), C.A. Redlich (Yale Occupational/Environmental, New Haven, CT, USA), J. Rooyackers (Netherlands Expertise Center for Occupational Respiratory Disorders - NECORD IRAS NKAL, Utrecht, the Netherlands), V. Schlünssen (Dept of Environmental and Occupational Medicine, School of Public Health, Århus University, Århus, Denmark), O. Vandenplas (Dept of Chest Medicine, MontGodinne Hospital, Université Catholique de Louvain, Yvoir, Belgium), and D. Wilken (Institute for Occupational and Maritime Medicine, University Medical Center Hamburg-Eppendorf, Hamburg, Germany).

The authors are grateful to B. Clin-Godard (CHRU de Caen, Caen, France), J. Sastre Dominguez (Servicio de Alergia, Fundacion Jimenez Diaz, Universidad Autonoma de Madrid, Madrid, Spain), S. Tarlo (Toronto Western Hospital University of Toronto, Toronto, ON, Canada), J-L. Malo (Hospital du Sacre Coeur, Universite du Montreal, Montreal, QC, Canada), and J. Walusiak (Dept of Occupational Diseases, Institute of Occupational Medicine, Lodz, Poland).

\section{REFERENCES}

1 Latza U, Baur X. Occupational obstructive airway diseases in Germany: frequency and causes in an international comparison. Am I Ind Med 2005; 48: 144-152.

2 Toren K, Blanc PD. Asthma caused by occupational exposures is common - a systematic analysis of estimates of the populationattributable fraction. BMC Pulm Med 2009; 9: 7.

3 Mannino DM. How much asthma is occupationally related? Occup Med 2000; 15: 359-368. 
4 Balmes J, Becklake M, Blanc P, et al. American Thoracic Society Statement: occupational contribution to the burden of airway disease. Am J Respir Crit Care Med 2003; 167: 787-797.

5 Blanc PD, Toren K. How much adult asthma can be attributed to occupational factors? Am J Med 1999; 107: 580-587.

6 Kogevinas M, Zock JP, Jarvis D, et al. Exposure to substances in the workplace and new-onset asthma: an international prospective population-based study (ECRHS-II). Lancet 2007; 370: 336-341.

7 Gautrin D, Ghezzo H, Infante-Rivard C, et al. Long-term outcomes in a prospective cohort of apprentices exposed to high-molecular-weight agents. Am J Respir Crit Care Med 2008; 177: 871-879.

8 Elliott L, Heederik D, Marshall S, et al. Incidence of allergy and allergy symptoms among workers exposed to laboratory animals. Occup Environ Med 2005; 62: 766-771.

9 Kruize H, Post W, Heederik D, et al. Respiratory allergy in laboratory animal workers: a retrospective cohort study using pre-employment screening data. Occup Environ Med 1997; 54: 830-835.

10 Blanc PD, Toren K. Occupation in chronic obstructive pulmonary disease and chronic bronchitis: an update. Int J Tuberc Lung Dis 2007; 11: 251-257.

11 Salvi SS, Barnes PJ. Chronic obstructive pulmonary disease in non-smokers. Lancet 2009; 374: 733-743.

12 Baur X, Sigsgaard T, Aasen T, et al. Guidelines on the management of work-related asthma. Eur Respir J 2012; 39: 529-545.

13 Mapp CE. Agents, old and new, causing occupational asthma. Occup Environ Med 2001; 58: 354-360.

14 Baur X. Airborne allergens and irritants in the workplace. In: Kay AB, Kaplan AP, Bousquet J, et al., eds. Allergy and Allergic Diseases. Oxford, Blackwell Publishing, 2008; pp. 1017-1122.

15 van Kampen V, Merget R, Baur X. Occupational airway sensitizers: an overview on the respective literature. Am J Ind Med 2000; 38: 164-218.

16 Newman Taylor AJ, Nicholson PJ, Cullinan P, et al., eds. Guidelines for the Prevention, Identification and Management of Occupational Asthma: Evidence Review and Recommendations. London, British Occupational Health Research Foundation, 2004.

17 Ameille J, Pauli G, Calastreng-Crinquand A, et al. Reported incidence of occupational asthma in France, 1996-99: the ONAP programme. Occup Environ Med 2003; 60: 136-141.

18 Brhel P. Occupational respiratory diseases in the Czech Republic. Ind Health 2003; 41: 121-123.

19 Cortona G, Pisati G, Dellabianca A, et al. Allergopatie professionali respiratorie: l'esperienza delle Unita Operative Ospedaliere di Medicina del Lavoro in Lombardia dal 1990 al 1998 [Respiratory occupational allergies: the experience of the Hospital Operative Unit of Occupational Medicine in Lombardy from 1990 to 1998]. G Ital Med Lav Ergon 2001; 23: 64-70.

20 Hnizdo E, Esterhuizen TM, Rees D, et al. Occupational asthma as identified by the Surveillance of Work-related and Occupational Respiratory Diseases programme in South Africa. Clin Exp Allergy 2001; 31: 32-39.

21 McDonald JC, Keynes HL, Meredith SK. Reported incidence of occupational asthma in the United Kingdom, 1989-97. Осcup Environ Med 2000; 57: 823-829.

22 Meredith SK, Taylor VM, McDonald JC. Occupational respiratory disease in the United Kingdom 1989: a report to the British Thoracic Society and the Society of Occupational Medicine by the SWORD project group. Br J Ind Med 1991; 48: 292-298.

23 Meyer JD, Holt DL, Cherry NM, et al. SWORD '98: surveillance of work-related and occupational respiratory disease in the UK. Occup Med (Lond) 1999; 49: 485-489.

24 Sallie BA, Ross DJ, Meredith SK, et al. SWORD '93. Surveillance of work-related and occupational respiratory disease in the UK. Occup Med (Lond) 1994; 44: 177-182.
25 Gannon PF, Burge PS. The SHIELD scheme in the West Midlands Region, United Kingdom. Midland Thoracic Society Research Group. Br J Ind Med 1993; 50: 791-796.

26 Toren $\mathrm{K}$, Balder B, Brisman J, et al. The risk of asthma in relation to occupational exposures: a case-control study from a Swedish city. Eur Respir J 1999; 13: 496-501.

27 Toren K, Jarvholm B, Brisman J, et al. Adult-onset asthma and occupational exposures. Scand J Work Environ Health 1999; 25 430-435.

28 Sigsgaard T, Heederik D, eds. Occupational Asthma. Basel, Birkhäuser, 2010.

29 Baur X. Mechanisms of allergic occupational asthma. In: Sigsgaard T, Heederik D, eds. Occupational Asthma. Basel, Birkhäuser, 2010; pp. 111-140.

30 Goe SK, Henneberger PK, Reilly MJ, et al. A descriptive study of work aggravated asthma. Occup Environ Med 2004; 61: 512-517.

31 Reijula K, Haahtela T, Klaukka T, et al. Incidence of occupational asthma and persistent asthma in young adults has increased in Finland. Chest 1996; 110: 58-61.

32 Karjalainen A, Kurppa K, Virtanen S, et al. Incidence of occupational asthma by occupation and industry in Finland. Am J Ind Med 2000; 37: 451-458.

33 Henneberger PK, Kreiss K, Rosenman KD, et al. An evaluation of the incidence of work-related asthma in the United States. Int J Occup Environ Health 1999; 5: 1-8.

34 Jaakkola JJ, Piipari R, Jaakkola MS. Occupation and asthma: a population-based incident case-control study. Am J Epidemiol 2003; 158: 981-987.

35 Johnson AR, Dimich-Ward HD, Manfreda J, et al. Occupational asthma in adults in six Canadian communities. Am J Respir Crit Care Med 2000; 162: 2058-2062.

36 Kogevinas M, Anto JM, Soriano JB, et al. The risk of asthma attributable to occupational exposures. A population-based study in Spain. Spanish Group of the European Asthma Study. Am J Respir Crit Care Med 1996; 154: 137-143.

37 Kogevinas M, Anto JM, Sunyer J, et al. Occupational asthma in Europe and other industrialised areas: a population-based study. European Community Respiratory Health Survey Study Group. Lancet 1999; 353; 1750-1754.

38 Vanhanen $\mathrm{M}$, Tuomi $\mathrm{T}$, Nordman $\mathrm{H}$, et al. Sensitization to industrial enzymes in enzyme research and production. Scand J Work Environ Health 1997; 23: 385-391.

39 Weill H, Waddell LG, Ziskind M. A study of workers exposed to detergent enzymes. J Am Med Assoc 1971; 217: 425-433.

40 Brisman J, Jarvholm B, Lillienberg L. Exposure-response relations for self reported asthma and rhinitis in bakers. Occup Environ Med 2000; 57: 335-340.

41 Brooks SM, Edwards JJ, Apol A, et al. An epidemiologic study of workers exposed to western red cedar and other wood dusts. Chest 1981; 80: 30-32.

42 Calverley AE, Rees D, Dowdeswell RJ, et al. Platinum salt sensitivity in refinery workers: incidence and effects of smoking and exposure. Occup Environ Med 1995; 52: 661-666.

43 Cathcart M, Nicholson P, Roberts D, et al. Enzyme exposure, smoking and lung function in employees in the detergent industry over 20 years. Medical Subcommittee of the UK Soap and Detergent Industry Association. Occup Med (Lond) 1997; 47: 473-478.

44 Coutts IL, Lozewicz S, Dally MB, et al. Respiratory symptoms related to work in a factory manufacturing cimetidine tablets. $\mathrm{Br}$ Med J (Clin Res Ed) 1984; 288: 1418.

45 Cullinan $\mathrm{P}$, Cook A, Gordon S, et al. Allergen exposure, atopy and smoking as determinants of allergy to rats in a cohort of laboratory employees. Eur Respir J 1999; 13: 1139-1143.

46 Cullinan P, Harris JM, Newman Taylor AJ, et al. An outbreak of asthma in a modern detergent factory. Lancet 2000; 356: 1899-1900. 
47 Cullinan P, Cook A, Nieuwenhuijsen MJ, et al. Allergen and dust exposure as determinants of work-related symptoms and sensitization in a cohort of flour-exposed workers; a case-control analysis. Ann Occup Hyg 2001; 45: 97-103.

48 Grammer LC, Shaughnessy MA, Lowenthal M, et al. Risk factors for immunologically mediated respiratory disease from hexahydrophthalic anhydride. J Occup Med 1994; 36: 642-646.

49 Hagmar L, Bellander T, Ranstam J, et al. Piperazine-induced airway symptoms: exposure-response relationships and selection in an occupational setting. Am J Ind Med 1984; 6: 347-357.

50 Heederik D, Houba R. An exploratory quantitative risk assessment for high molecular weight sensitizers: wheat flour. Ann Occup Hyg 2001; 45: 175-185.

51 Houba R, Heederik D, Doekes G. Wheat sensitization and workrelated symptoms in the baking industry are preventable. An epidemiologic study. Am J Respir Crit Care Med 1998; 158: 1499-1503.

52 Juniper CP, How MJ, Goodwin BF, et al. Bacillus subtilis enzymes: a 7-year clinical, epidemiological and immunological study of an industrial allergen. J Soc Occup Med 1977; 27: 3-12.

53 Liss GM, Bernstein D, Genesove L, et al. Assessment of risk factors for IgE-mediated sensitization to tetrachlorophthalic anhydride. J Allergy Clin Immunol 1993; 92: 237-247.

54 Musk AW, Venables KM, Crook B, et al. Respiratory symptoms, lung function, and sensitisation to flour in a British bakery. $\mathrm{Br} J$ Ind Med 1989; 46: 636-642.

55 Osterman K, Zetterstrom O, Johansson SG. Coffee worker's allergy. Allergy 1982; 37: 313-322.

56 McSharry C, Anderson K, McKay IC, et al. The IgE and IgG antibody responses to aerosols of Nephrops norvegicus (prawn) antigens: the association with clinical hypersensitivity and with cigarette smoking. Clin Exp Immunol 1994; 97: 499-504.

57 Meredith SK, Bugler J, Clark RL. Isocyanate exposure and occupational asthma: a case-referent study. Occup Environ Med 2000; 57: 830-836.

58 Platts-Mills TA, Longbottom J, Edwards J, et al. Occupational asthma and rhinitis related to laboratory rats: serum IgG and IgE antibodies to the rat urinary allergen. J Allergy Clin Immunol 1987, 79: 505-515.

59 Tarlo SM, Liss GM, Dias C, et al. Assessment of the relationship between isocyanate exposure levels and occupational asthma. Am J Ind Med 1997; 32: 517-521.

60 Cullinan P, Lowson D, Nieuwenhuijsen MJ, et al. Work related symptoms, sensitisation, and estimated exposure in workers not previously exposed to laboratory rats. Occup Environ Med 1994; 51: 589-592.

61 Ortega HG, Daroowalla F, Petsonk EL, et al. Respiratory symptoms among crab processing workers in Alaska: epidemiological and environmental assessment. Am J Ind Med 2001; 39: 598-607.

62 Chan-Yeung M, Malo JL. Occupational asthma. N Engl J Med 1995; 333: 107-112.

63 Masoli M, Fabian D, Holt S, et al. The global burden of asthma: executive summary of the GINA Dissemination Committee report. Allergy 2004; 59: 469-478.

64 Karjalainen A, Kurppa K, Martikainen R, et al. Work is related to a substantial portion of adult-onset asthma incidence in the Finnish population. Am J Respir Crit Care Med 2001; 164: 565-568.

65 Fishwick D, Bradshaw LM, D'Souza W, et al. Chronic bronchitis, shortness of breath, and airway obstruction by occupation in New Zealand. Am I Respir Crit Care Med 1997; 156: 1440-1446.

66 Kraut A, Walld R, Mustard C. Prevalence of physiciandiagnosed asthma by occupational groupings in Manitoba, Canada. Am J Ind Med 1997; 32: 275-282.

67 de Bono J, Hudsmith L. Occupational asthma: a community based study. Occup Med (Lond) 1999; 49: 217-219.
68 Meyer JD, Holt DL, Chen Y, et al. SWORD '99: surveillance of work-related and occupational respiratory disease in the UK. Occup Med (Lond) 2001; 51: 204-208.

69 Bakke JV, Nordman H. Epidemiological evidence of increase in allergy and other hypersensitivity in the airways. In: Flyvholm MA, ed. Criteria for Classification of Skin-and Airway-Sensitizing Substances in the Work and General Environments. Copenhagen, WHO Regional Office for Europe, 1997; pp. 42-62.

70 Gautrin D, Ghezzo H, Infante-Rivard C, et al. Incidence and determinants of IgE-mediated sensitization in apprentices. A prospective study. Am J Respir Crit Care Med 2000; 162: 1222-1228.

71 Nicholson PJ, Cullinan P, Taylor AJ, et al. Evidence based guidelines for the prevention, identification, and management of occupational asthma. Occup Environ Med 2005; 62: 290-299.

72 Tarlo SM, Boulet LP, Cartier A, et al. Canadian Thoracic Society guidelines for occupational asthma. Can Respir J 1998; 5: 289-300.

73 Liss GM, Tarlo SM, Banks D, et al. Preliminary report of mortality among workers compensated for work-related asthma. Am J Ind Med 1999; 35: 465-471.

74 Liss GM, Tarlo SM, Macfarlane Y, et al. Hospitalization among workers compensated for occupational asthma. Am J Respir Crit Care Med 2000; 162: 112-118.

75 Vandenplas O. Socioeconomic impact of work-related asthma. Expert Rev Pharmacoecon Outcomes Res 2008; 8: 395-400.

76 Boyd R, Cowie H, Hurley F, et al. The True Cost of Occupational Asthma in Great Britain. Research Report 474. Suffolk, Health and Safety Executive, 2006.

77 Leigh JP, Romano PS, Schenker MB, et al. Costs of occupational COPD and asthma. Chest 2002; 121: 264-272.

78 Gannon PF, Weir DC, Robertson AS, et al. Health, employment, and financial outcomes in workers with occupational asthma. $\mathrm{Br}$ J Ind Med 1993; 50: 491-496.

79 Ameille J, Pairon JC, Bayeux MC, et al. Consequences of occupational asthma on employment and financial status: a follow-up study. Eur Respir J 1997; 10: 55-58.

80 Piirila PL, Keskinen HM, Luukkonen R, Salo et al. Work, unemployment and life satisfaction among patients with diisocyanate induced asthma - a prospective study. J Occup Health 2005; 47: 112-118.

81 Lemiere C, Forget A, Dufour $\mathrm{MH}$, et al. Characteristics and medical resource use of asthmatic subjects with and without work-related asthma. J Allergy Clin Immunol 2007; 120: 1354-1359.

82 Malo JL, Boulet LP, Dewitte JD, et al. Quality of life of subjects with occupational asthma. J Allergy Clin Immunol 1993; 91: 1121-1127.

83 Miedinger D, Lavoie KL, L'Archeveque J, et al. Quality-of-life, psychological, and cost outcomes 2 years after diagnosis of occupational asthma. J Occup Environ Med 2011; 53: 231-238.

84 Yacoub MR, Lavoie K, Lacoste G, et al. Assessment of impairment/disability due to occupational asthma through a multidimensional approach. Eur Respir J 2007; 29: 889-896.

85 Vandenplas O, Henneberger PK. Socioeconomic outcomes in work-exacerbated asthma. Curr Opin Allergy Clin Immunol 2007; 7: 236-241.

86 Meijer E, Grobbee DE, Heederik D. Detection of workers sensitised to high molecular weight allergens: a diagnostic study in laboratory animal workers. Occup Environ Med 2002; 59: 189-195.

87 Meijer E, Grobbee DE, Heederik D. A strategy for health surveillance in laboratory animal workers exposed to high molecular weight allergens. Occup Environ Med 2004; 61: 831-837.

88 Suarthana E, Vergouwe Y, Nieuwenhuijsen M, et al. Diagnostic model for sensitization in workers exposed to occupational high molecular weight allergens. Am I Ind Med 2005; 48: 168-174.

89 Suarthana E, Meijer E, Grobbee DE, et al. Predicting occupational diseases. Occup Environ Med 2009; 66: 713-714. 
90 Meijster T, Warren N, Heederik D, et al. What is the best strategy to reduce the burden of occupational asthma and allergy in bakers? Occup Environ Med 2011; 68: 176-182.

91 Wilken D, Baur X, Barbinova L, et al. What are the benefits of medical screening and surveillance? Eur Respir Rev 2012; 124: 105-111.

92 Heederik D, Henneberger PK, Redlich CA. Primary prevention: exposure reduction, skin exposure and respiratory protection. Eur Respir Rev 2012; 124: 112-124.

93 Vandenplas O, Dressel H, Nowak D, et al. What is the optimal management option for occupational asthma? Eur Respir Rev 2012; 124; 97-104.

94 Cullinan P, Tarlo S, Nemery B. The prevention of occupational asthma. Eur Respir J 2003; 22: 853-860.

95 Moscato G, Vandenplas O, Gerth Van Wijk R, et al. Occupational rhinitis. Allergy 2008; 63: 969-980.

96 Moscato G, Dellabianca A, Perfetti L, et al. Occupational asthma: a longitudinal study on the clinical and socioeconomic outcome after diagnosis. Chest 1999; 115: 249-256.

97 Vandenplas O, Toren K, Blanc PD. Health and socioeconomic impact of work-related asthma. Eur Respir J 2003; 22: 689-697.

98 Sarlo K. Control of occupational asthma and allergy in the detergent industry. Ann Allergy Asthma Immunol 2003; 90: 32-34.

99 Hughes EG. Medical surveillance of platinum refinery workers. J Soc Occup Med 1980; 30: 27-30.

100 Gordon S, Preece R. Prevention of laboratory animal allergy. Occup Med (Lond) 2003; 53: 371-377.

101 LaMontagne AD, Radi S, Elder DS, et al. Primary prevention of latex related sensitisation and occupational asthma: a systematic review. Occup Environ Med 2006; 63: 359-364.

102 Rijnkels JM, Smid T, Van den Aker EC, et al. Prevention of workrelated airway allergies; summary of the advice from the Health Council of the Netherlands. Allergy 2008; 63: 1593-1596.

103 Maestrelli $\mathrm{P}$, Schlünssen V, Mason $\mathrm{P}$, et al. Contribution of host factors and workplace exposure to the outcome of occupational asthma. Eur Respir Rev 2012; 124: 88-96.

104 Braman SS, Barrows AA, DeCotiis BA, et al. Airway hyperresponsiveness in allergic rhinitis. A risk factor for asthma. Chest 1987; 91: 671-674.

105 Elliott L, Heederik D, Marshall S, et al. Progression of selfreported symptoms in laboratory animal allergy. J Allergy Clin Immunol 2005; 116: 127-132.

106 Gautrin D, Ghezzo H, Infante-Rivard C, et al. Natural history of sensitization, symptoms and occupational diseases in apprentices exposed to laboratory animals. Eur Respir J 2001; 17: 904-908.

107 Gautrin D, Infante-Rivard C, Ghezzo H, et al. Incidence and host determinants of probable occupational asthma in apprentices exposed to laboratory animals. Am J Respir Crit Care Med 2001; 163: 899-904.

108 Karjalainen A, Martikainen R, Klaukka T, et al. Risk of asthma among Finnish patients with occupational rhinitis. Chest 2003; 123: 283-288.

109 Tarlo SM, Liss GM. Occupational asthma: an approach to diagnosis and management. CMAJ 2003; 168: 867-871.

110 Sox HC, Blatt MA, Higgins MC, et al., eds. Medical Decision Making. Boston, Butterworths, 1988.

111 Drummond MF, Stoddart GL, Torrance G, eds. Method of Economic Evaluation of Health Care Programes. Oxford, Oxford Medical Publications, 1987.

112 Vineis P. Evidence-based primary prevention? Scand J Work Environ Health 2000; 26: 443-448.

113 Weinstein M, Fineberg HV, eds. Clinical Decision Analysis. London, Saunders, 1980.

114 Committee on Risk Assessment of Hazardous Air Pollutants CoLSNRC. Science and Judgement in Risk Assessment. Washington, National Academy Press, 1994.
115 Commission of the European Communities: Commission recommendation of 19 September 2003 concerning the European schedule of occupational diseases. Official Journal of the EU 2003; L238: 28-34.

116 Aw T-C, Ahmed S, Choudat D. Information notices on occupational diseases: a guide to diagnosis. Luxembourg, Office for Official Publications of the European Communities, 2009.

117 Barth PS, Hunt HA. Worker's Compensation and Work-Related Illnesses and Disease. Cambridge, MIT Press, 1982.

118 Massarelli N, Giovannola D, Wozowczyk M. EU-27 employment and unemployment levels stable. Latest labour market trendsthird-quarter 2010 data. Eurostat Statistics in focus 2011; 8: 1-12.

119 International Labour Organization. Table 1a Labour force participation rate (ILO estimates; by sex and age group). KILM 6th Edn. http://kilm.ilo.org/KILMnetBeta/default2.asp

120 Statistics Canada. Labour force characteristics, seasonally adjusted, by province (monthly) (Quebec, Ontario, Manitoba). www 40 statcan.gc.ca/101/cst01/lfss01b-eng.htm Date last accessed: Janurary 23, 2003.

121 Bernstein IL, Keskinen H, Blanc PD, et al. Medicolegal aspects, compensation aspects, and evaluation of impairment/disability. In: Bernstein IL, Chan-Yeung M, Malo JL, et al., eds. Asthma in the Workplace. 3rd Edn. New York, Taylor and Francis Group, 2006; pp. 319-352.

122 Richman SI. Why change? A look at the current system of disability determination and workers' compensation for occupational lung disease. Ann Intern Med 1982; 97: 908-914.

123 Blessman JE. Differential treatment of occupational disease $v$ occupational injury by workers' compensation in Washington State. J Occup Med 1991; 33: 121-126.

124 Kimber I, Kerkvliet NI, Taylor SL, et al. Toxicology of protein allergenicity: prediction and characterization. Toxicol Sci 1999; 48: 157-162.

125 Robinson MK, Horn PA, Kawabata TT, et al. Use of the mouse intranasal test (MINT) to determine the allergenic potency of detergent enzymes: comparison to the guinea pig intratracheal (GPIT) test. Toxicol Sci 1998; 43: 39-46.

126 Dearman RJ, Basketter DA, Kimber I. Local lymph node assay: use in hazard and risk assessment. J Appl Toxicol 1999; 19: 299-306.

127 Dearman RJ, Kimber I. Cytokine fingerprinting and hazard assessment of chemical respiratory allergy. J Appl Toxicol 2001; 21: 153-163.

128 Plitnick LM, Loveless SE, Ladics GS, et al. Cytokine profiling for chemical sensitizers: application of the ribonuclease protection assay and effect of dose. Toxicol Appl Pharmacol 2002; 179: 145-154.

129 Vandebriel RJ, De Jong WH, Spiekstra SW, et al. Assessment of preferential T-helper 1 or T-helper 2 induction by low molecular weight compounds using the local lymph node assay in conjunction with RT-PCR and ELISA for interferon-gamma and interleukin-4. Toxicol Appl Pharmacol 2000; 162: 77-85.

130 Briatico-Vangosa G, Braun CL, Cookman G, et al. Respiratory allergy: hazard identification and risk assessment. Fundam Appl Toxicol 1994; 23: 145-158.

131 Seed M, Agius R. Further validation of computer-based prediction of chemical asthma hazard. Occup Med (Lond) 2010; 60: $115-120$.

132 Jarvis J, Seed MJ, Elton R, et al. Relationship between chemical structure and the occupational asthma hazard of low molecular weight organic compounds. Occup Environ Med 2005; 62: 243-250.

133 Jarvis J. Chemical asthma hazard assessment program instructions. http://homepages.ed.ac.uk/jjarvis/research/hazassess/ instructions.html Date last accessed: January 23, 2012.

134 Bousquet J, Khaltaev N, Cruz AA, et al. Allergic rhinitis and its impact on asthma (ARIA) 2008 update (in collaboration with the World Health Organization, GA ${ }^{2} \mathrm{LEN}$ and AllerGen). Allergy 2008; 63: 8-160. 
135 Fokkens W, Lund V, Bachert C, et al. EAACI position paper on rhinosinusitis and nasal polyps executive summary. Allergy 2005; 60: 583-601.

136 Fokkens W, Lund V, Mullol J. European position paper on rhinosinusitis and nasal polyps. Rhinology 2007; 45: 1-139.

137 Spector SL, Nicklas RA, Chapman JA, et al. Symptom severity assessment of allergic rhinitis: part 1. Ann Allergy Asthma Immunol 2003; 91: 105-114.

138 Cockroft DW, Hargreave FE. Airway hyperresponsiveness. Relevance of random population data to clinical usefulness. Am Rev Respir Dis 1990; 142: 497-500.

139 Bateman ED, Hurd SS, Barnes PJ, et al. Global strategy for asthma management and prevention: GINA executive summary. Eur Respir J 2008; 31: 143-178.

140 Global Initiative for Asthma. Global Strategy for Asthma Management and Prevention. Updated 2010. Date last accessed: Janruary 23, 2012. Available from: www.ginasthma.org.

141 Vandenplas O, Malo JL. Definitions and types of work-related asthma: a nosological approach. Eur Respir J 2003; 21: 706-712.

142 Tarlo SM, Balmes J, Balkissoon R, et al. Diagnosis and management of work-related asthma: American College of Chest Physicians Consensus Statement. Chest 2008; 134: 1-41.

143 Nicholson PJ, Cullinan P, Burge PS, et al. Occupational Asthma: Prevention, Identification and Management: Systematic Review and Recommendations. London, British Occupational Health Research Foundation, 2010.

144 Feinstein AR, Horwitz RI. Problems in the "evidence" of "evidence-based medicine". Am J Med 1997; 103: 529-535.

145 Miettinen OS. Evidence in medicine: invited commentary. CMAJ 1998; 158: 215-221.

146 Miettinen OS. Evidence-based medicine, case-based medicine; scientific medicine, quasi-scientific medicine. Commentary on
Tonelli (2006), Integrating evidence into clinical practice: an alternative to evidence-based approaches. J Eval Clin Pract 2006; 12: $260-264$.

147 Tobin MJ. Counterpoint: evidence-based medicine lacks a sound scientific base. Chest 2008; 133: 1071-1074.

148 Beach J, Rowe BH, Blitz S, et al. Diagnosis and management of work-related asthma. Evid Rep Technol Assess 2005; 1-8.

149 Lijmer JG, Mol BW, Heisterkamp S, et al. Empirical evidence of design-related bias in studies of diagnostic tests. JAMA 1999; 282: 1061-1066.

150 Newman Taylor AJ, Cullinan P, Burge PS, et al. BOHRF guidelines for occupational asthma. Thorax 2005; 60: 364-366.

151 Yamada S, Slingsby BT, Inada MK, et al. Evidence-based public health: a critical perspective. J Public Health 2008; 16: 169-172.

152 Sackett DL, Rosenberg WM, Gray JA, et al. Evidence based medicine: what it is and what it isn't. BMJ 1996; 312: 71-72.

153 Guyatt G, Cook D, Haynes B. Evidence based medicine has come a long way. BMJ 2004; 329: 990-991.

154 Strauss SE, McAllister FA. Evidence-based medicine: a commentary on common criticisms. CMAJ 2000; 163: 837-841.

155 Ernst P, Fitzgerald JM, Spier S. Canadian Asthma Consensus Conference. Summary of recommendations. Can Respir J 1996; 3: 89-101.

156 Harbour R, Miller J. A new system for grading recommendations in evidence based guidelines. BMJ 2001; 323: 334-336.

157 Royal College of General Practitioners. The Development and Implementation of Clinical Guidelines. Report of the Clinical Guidelines Working Group. London, Royal College of General Practitioners, 1995.

158 Fishwick D, Barber CM, Bradshaw LM, et al. Standards of care for occupational asthma. Thorax 2008; 63: 240-250. 